\title{
CONTÁGIO INTRADOMICILIAR E STATUS VACINAL ENTRE COMUNICANTES DE PORTADORES DO VÍRUS DA HEPATITE B
}

Candida Maria Abrahão de Oliveira ${ }^{1}$

Alex Junior Souza de Souza ${ }^{1}$

Maria de Jesus de Sousa Brasil ${ }^{1}$

Manoel do Carmo Pereira Soares ${ }^{1}$

Heloisa Marceliano Nunes ${ }^{1}$

Márcio Roberto Teixeira Nunes ${ }^{1}$

\begin{abstract}
https://orcid.org/0000-0001-6253-7477
https://orcid.org/0000-0001-6201-2777

https://orcid.org/0000-0002-8002-9406

https://orcid.org/0000-0001-7863-3113

https://orcid.org/0000-0002-9335-6932

https://orcid.org/0000-0001-9739-5499
\end{abstract}

Objetivo: Avaliar a cobertura da vacina contra hepatite B e a frequência da infecção em comunicantes de portadores do Vírus da Hepatite $B$ vinte anos após a implementação da vacina na cidade de Belém, Pará, Brasil. Método: Estudo descritivo quantitativo, desenvolvido entre 2016 e 2018 . Foram realizadas visitas domiciliares aos portadores do vírus, notificados por meio da busca de comunicantes, com orientações sobre a pesquisa, preenchimento e assinatura de formulários, coleta de amostras para testes sorológicos de hepatite B (HBsAg, anti-HBc total, anti-HBs) por técnica imunoenzimática. Resultados: Na população analisada 53,5\% são do sexo masculino, com média de idade de 9,4 anos (entre 4 meses a 19 anos com mediana de 10 anos). Não foram detectados portadores de HBsAg reagente; anti-HBc isolado total foi detectado em 2,1\%; 4,2\% eram anti-HBc total / anti-HBs reagente e 42\% anti-HBs isolado, atribuídos à vacinação; 41,7\% receberam esquema vacinal completo e 58,3\% eram suscetíveis. Conclusões: Os resultados encontrados podem ser utilizados como norteadores de ações estratégicas visando ampliar a cobertura vacinal e reduzir a prevalência de infectados na população de comunicantes intradomiciliares.

Descritores: Estudo soroepidemiológico; Hepatite B; Contato; Vacina.

\section{HOUSE HOLD CONTAGION AND VACCINATION STATUS AMONG COMMUNICANTS OF HEPATITIS B VIRUS CARRIERS}

Objective: To evaluate the coverage of the hepatitis B vaccine and the frequency of infection in communicants of Hepatitis B virus carriers twenty years after the vaccine was implemented in the city of Belém, Pará, Brazil. Method: Quantitative descriptive study developed between 2016 and 2018. Home visits were carried out to the carriers of the virus notified through the search for communicants, with guiding on research, filling and signing forms, collecting samples for serological tests for Hepatitis $B$ (HBsAg, total anti - HBc, anti - HBs) by immunoenzymatic technique. Results: In the population analyzed $53.5 \%$ are male, with a mean age of 9.4 years (ranging from 4 months to 19 years and median of 10 years). Carriers HBsAg reagent were not detected; total anti - HBc isolated was detected in $2.1 \%$; $4.2 \%$ were total anti - HBc / anti - HBs reagent and $42 \%$ anti - HBs alone, attributed to vaccination; $41.7 \%$ received a complete vaccination schedule and $58.3 \%$ were susceptible. Conclusions:The results found can be used as guidelines for strategic actions aimed at expanding vaccine coverage and reducing the prevalence of infected people in the population of household communicators.

Descriptors: Serumepidemiology study Hepatitis B; Contact; Vaccine.

\section{CONTAGIO INTRADOMICILIAR Y ESTADO DE VACUNACIÓN ENTRE CONTACTOS DE PORTADORES DEL VIRUS DE HEPATITIS B}

Objetivo: Evaluar la cobertura de la vacuna contra la hepatitis B y la frecuencia de infección en portadores del Virus de la Hepatitis B veinte años después de la implementación de la vacuna em la ciudad de Belém, Pará, Brasil. Método: Estudio descriptivo cuantitativo realizado entre 2016 y 2018. Fueron realizadas visitas domiciliarias a los portadores del vírus, notificados a través de la búsqueda de domiciliares, com orientaciones sobre la investigación, registro y asignatura de formularios, toma de muestras de sangre para pruebas serológicas de Hepatitis B (HBsAg, anti-HBc total, anti-HBs) por la técnica inmunoenzimática. Resultados: Em lapoblación analizada 53,5\% del sexo masculino, com edad promedio de 9,4 años (entre 4 meses a 19 años con mediana de 10 años) no fueron detectados portadores de HBsAg reactivo; el total de anti-HBc fué detectado en 2,1\%; 4,2\% anti-HBc total/anti-HBs reactivo, y, 42\% anti-HBs aislado, atribuido a la vacunación; 41,7\% recibieron el esquema completo de vacunación y 58,3\% fueron susceptibles. Conclusiones: Los resultados encontrados pueden usarse como pautas para acciones estratégicas dirigidas a ampliar la cobertura de vacunación y reducir la prevalencia de personas infectadas em la población de comunicadores domésticos.

Descritores: Estudioseroepidemiologico; Hepatitis B; Contacto; Vacuna.

${ }^{1}$ Instituto Evandro Chagas. Secretaria de Vigilância em Saúde, Ministério da Saúde, Belém, PA, Brasil.

Autor Correspondente: Candida Maria Abrahão de Oliveira Email: candidaoliveira@iec.gov.br Recebido: 06/4/20 Aceito: 05/6/20 


\section{INTRODUÇÃO}

A hepatite B, causada pelo Vírus da Hepatite B (VHB), representa um grave problema de saúde pública mundial, mesmo sendo uma doença imunoprevenível por vacina de alta segurança e imunogenicidade ${ }^{1-2}$. O VHB tem tropismo por hepatócitos e pode produzir perfil de infecção aguda e/ou crônica em seres humanos, resultando em quadros clínicos variando de hepatite aguda ou fulminante a hepatite crônica, com progressão para fibrose/cirrose hepática e formação de carcinoma hepatoocelular-2

A infecção por VHB tem ampla distribuição pelo mundo e, segundo características populacionais e epidemiológicas, a prevalência pode variar de acordo com a distribuição geográfica analisada, porém, com prevalências superiores em países subdesenvolvidos em desenvolvimento ${ }^{3-4}$.

Portadores de infecção por VHB podem transmitir o vírus a indivíduos suscetíveis, por via sexual ou a partir de contato com sangue contaminado (por via parenteral, percutânea ou transmissão vertical) ${ }^{1,5}$. Neste sentido, objetos que podem produzir escarificação e sangramentos na pele ou em mucosas, quando contaminado com sangue de portadores do VHB e compartilhados, podem representar importantes veículos de transmissão intrafamiliar ou intradomiciliar do agente ${ }^{1,6}$.

O período de incubação do VHB varia em média de 60 a 90 dias, com as primeiras manifestações de sintomas e sinais clínicos de duas a três semanas após a infecção, período de infecção aguda em que o marcador de replicação viral (HbsAg antígeno de superfície do VHB) pode ser detectável sorologicamente ${ }^{1,6}$. Indivíduos com infecção aguda ou crônica podem ser fontes de infecção pelo VHB, inclusive por vários anos, no caso de portadores crônicos ${ }^{6-7}$.

Fatores de risco como hábitos de relações sexuais sem proteção, múltiplos parceiros sexuais, uso indiscriminado de álcool e drogas injetáveis, aplicação de tatuagem e piercings podem aumentar os riscos de infecção por VHB, sobretudo entre adolescentes e adultos jovens, faixas etárias em que algumas destas características psicossociais e comportamentais podem ser favorecidas ${ }^{8}$.

O tratamento das formas agudas da infecção pelo VHB continua inespecífico, sendo indicado apenas o uso de sintomáticos e para as formas crônicas do VHB, no Brasil tem-se utilizado o Protocolo Clínico e Diretrizes Terapêuticas para Hepatite B e Coinfecções ${ }^{5}$.

Na prevenção da infecção pelo VHB, são usadas a imunização ativa e/ou passiva e quimioprofilaxia antiviral. A vacina hepatite B é responsável pela imunização ativa, é segura e confere imunidade por longo prazo, em grande número dos indivíduos saudáveis, tem na sua composição o antígeno de superfície do VHB. A imunização passiva é realizada com o uso da Imunoglobulina Humana Anti-Hepatite B (IGHAHB) que contém elevados títulos de anticorpos específicos. A IGHAHB deve ser administrada juntamente com a vacina contra hepatite $\mathrm{B}$ em neonatos e indivíduos expostos a situações de risco, tem a finalidade de prevenir a transmissão vertical e realizar a profilaxia pós-exposição. Nos portadores do VHB se utiliza com a finalidade de evitar a reinfecção ao serem submetidos a transplante de fígado?

Dentro do Sistema Nacional de Vigilância Epidemiológica (SNVE), consolidado pela Portaria № 4, de 28 de setembro de 2017 e alterado pela Portaria № 264, de 17 de fevereiro de 2020, ambas do Ministério da Saúde, as hepatites virais estão incluidas na lista nacional de doenças, agravos e eventos saúde pública de notificação compulsória, com periodicidade de notificação semanal ao Sistema Único de Saúde (SUS) ${ }^{10}$

Neste sentido, o estudo teve como objetivo avaliar a cobertura da vacina contra hepatite $B$ e a frequência da infecção em comunicantes de portadores do Vírus da Hepatite $B$ vinte anos após a implementação da vacina na cidade de Belém, Pará, Brasil.

\section{MÉTODO}

\section{Tipo de estudo}

Estudo descritivo, de abordagem quantitativa, com utilização de estratégia de busca ativa intradomiciliar de casos entre comunicantes de portadores do VHB.

\section{Participantes do estudo}

Para o cálculo do número mínimo de participantes e triagem de comunicantes da pesquisa, foram utilizados dados de notificação do Ministério da Saúde, período de 19982018, obtidos no banco de dados da Seção de Hepatologia (SAHEP) do Instituto Evandro Chagas (IEC), da Secretaria de Vigilância em Saúde (SVS), do Ministério da Saúde e do Sistema de Informação de Agravos de Notificação (SINAN).

Considerando o universo de 837 casos de hepatite B notificados no período, com nível de confiança de $95 \%$ e margem de erro de 5\%, o número mínimo de comunicantes incluídos no estudo foi determinado a partir do cálculo apresentado na Figura 1.

$$
\begin{aligned}
& \mathrm{no}_{\mathrm{o}}=\frac{1}{E^{2}}=\frac{1}{(0,05)^{2}}=\frac{1}{0,0025}=400 \\
& \mathrm{n}=\frac{\mathrm{n}_{\mathrm{o}} \times 400}{\mathrm{n}_{\mathrm{o}}+400}-\frac{400 \times 837}{400+837}- \\
& \mathrm{n}=\frac{334.800}{1.237}=270,65=271 \text { participantes } \\
& \mathrm{n}_{\mathrm{O}=\text { Tamanho amostral inicial considerando um erro de } 5 \% ; \mathrm{E}^{2}=\text { margem de erro } \mathrm{n} \text { = número }}
\end{aligned}
$$

Enferm. Foco 2020; 11 (3): 144-151 | 145 
Foi estimado para o estudo o " $n$ " amostral mínimo de 271 participantes, ao final da pesquisa participaram 288 individuos ( $n=288$ ). Foram utilizados como critérios de inclusão no estudo indivíduos considerados comunicantes de portadores de hepatite $B$, moradores de um mesmo domicílio, de ambos os sexos, com idade de até 19 anos (considerando o período do início da vacinação no município), residentes na cidade de Belém do Pará, que voluntariamente aceitaram participar da pesquisa e excluídos indivíduos que declararam não residir ou ter contato domiciliar com infectados por VHB, de faixa etária superior a 20 anos ou que não aceitaram participar da pesquisa.

Foram consideradas comunicantes as pessoas com proximidade ou relação com indivíduo infectado pelo $\mathrm{VHB}$ e convívio em ambiente domiciliar com portadores de hepatite B, estando, portanto, expostos a possibilidade de contrair a infecção ${ }^{11}$.

\section{Local do estudo}

O estudo foi desenvolvido no Município de Belém, Pará, Brasil.

\section{Coleta dos dados com explicitação dos instrumentos} e procedimentos

A etapa de coleta de dados e amostras biológicas ocorreu no período de junho de 2016 a julho de 2018.

A pesquisa ao ser desenvolvida foi executada em quatro etapas principais:

la Etapa - levantamento de casos notificados de hepatite $B$ e triagem de comunicantes de portadores do VHB, nos bancos de dados da SAHEP ou do SINAN;

2a Etapa - Contato preliminar com portadores de VHB e/ ou familiares, para convite para participação na pesquisa e solicitação de autorização para visita domiciliar. Os dados de contato telefônico e/ou endereço residencial, foram obtidos por meio dos bancos de dados, ocasião em que eram realizados esclarecimentos sobre os objetivos, finalidades do estudo e agendamento de visitas domiciliares pela equipe do estudo;

3a etapa - Visita domiciliar com orientações sobre os objetivos e finalidades da pesquisa, obtenção de aceite de participação, com assinatura de Termo de Consentimento Livre e Esclarecido (TCLE)/Termo de Assentimento Livre e Esclarecido (TALE), aplicado a indivíduos menores de 18 anos, assinado pelos seus representantes legais. Aplicada a Ficha de Inquérito Individual para obtenção de dados demográficos e epidemiológicos dos participantes, bem como avaliação da caderneta de vacinação para os que possuíam o documento e coleta de amostras biológicas para testes sorológicos e moleculares para VHB. Uma amostra de cerca de $8 \mathrm{~mL}$ sangue foi coletada de cada participante, por meio de punção venosa com agulha e tubo tipo Vacutainer ${ }^{\circledR}$, sem anticoagulante, para posterior obtenção de soro, utilizado na realização de exames laboratoriais para pesquisa de infecção por VHB.

4a Etapa - Processamento laboratorial, análise de marcadores sorológicos e perfis de infecção para hepatite B e dos dados demográficos e epidemiológicos.

Foram analisados os marcadores sorológicos HBsAg, anti-HBc total e anti-HBs, utilizando kits comerciais dos laboratórios Biomérieux ${ }^{\circledR}$ e/ou Biolisa ${ }^{\circledR}$ (Lyon, França), Dia.Pro ${ }^{\circledR}$ (Milão, Itália) e SYM - Symbiosys ${ }^{\circledR}$ (São Paulo, Brasil), respectivamente, por técnica imunoenzimática (ELISA).

As amostras positivas ou inconclusivas para anti-HBc isolado foram encaminhadas para detecção molecular utilizando na extração do DNA viral o kit OIAamp MinEluteVirus Spin (OIAGEN) conforme as instruções do fabricante e submetido à amplificação por Nested-PCR de um fragmento de 734 pb da região S/POL viral, genes que codificam o HBsAg e a polimerase viral. Nos testes de Nested-PCR, foram utilizados os primers FHBS1, 5'- GAG TCT AGA CTC GTG GTG GAC TTC3' e RADElM, 5'- TGC RTC AGC AAA CAC TTG GC-3', no primeiro round de PCR e os primers FHBS2, 5' - CGT GGT GGA CTT CTC TCA ATT TTC- 3', e RADE2M, 5'- TGR CAN ACY TTC CAR TCA ATN GG-3; segundo condições de termociclagem descritas previamente ${ }^{12-13}$. Os amplicons foram submetidos a eletroforese em gel de agarose $1 \%$ e produtos com tamanho próximo ao tamanho esperado (734 pb) foram considerados como positivos.

\section{Procedimentos de análise dos dados}

Os resultados foram armazenados na base de dados da SAHEP/IEC (Hepatoware) e as análises estatísticas conduzidas empregando-se os softwares EPIINFO 2007, versão 7.1.0.6 e BioEstat 5.0.

Para a medida de tendência central utilizada pelo tempo decorrido entre a terceira/quarta dose da vacina e a coleta de sangue foi feita pelo cálculo da média. Por comparação simples e univariada foi utilizado o teste Qui-quadrado para análise da associação entre as variáveis: sexo, dose da vacina e marcador sorológico anti-HBc reagente isolado, todos utilizando o nível de significância estatística de $5 \%$ $(p \leq 0,05)$.

\section{Procedimentos éticos}

A execução do projeto foi aprovada por Comitê de Ética e Pesquisa envolvendo Seres Humanos do IEC, sob Parecer $n$ ㅇ 1.436.848, atendendo à Resolução № 466/2012 do Conselho Nacional de Saúde (CNS). Todos os participantes ou representantes legais assinaram o TCLE e o TALE (menores de 18 anos). Os nomes foram substituidos pelas iniciais e por número de identificação das amostras biológicas. 


\section{RESULTADOS}

A maior frequência de coletas ocorreu nos bairros do Bengui (11,8\%, 34/288); Guamá (11,5\% - 33/288), Val-de-Cães (8,7\% - 25/288), Jurunas (8,3\% - 24/288), Pedreira (6,9\% 20/288), Marco e Tapanã (5,9\% - 17/288, respectivamente), Terra Firme (5,2\% - 15/288) e Campina de Icoaraci (3,5\% 10/288). Os demais 32,3\% (93/288) estavam distribuidos por outros bairros da cidade de Belém.
A amostra constituiu-se de 53,5\% (154/288) de indivíduos do sexo masculino. A média de idade foi de nove anos, com variação de quatro meses a 19 anos de idade e mediana de dez anos. A maior frequência de individuos foi encontrada entre 10 e 14 anos $(29,2 \%-84 / 288)$ e a menor entre os menores de ano de idade $(3,8 \%-11 / 288)$, conforme apresentado na Tabela 1.

\begin{tabular}{|c|c|c|c|}
\hline \multirow{2}{*}{$\begin{array}{l}\text { Faixa etária } \\
\text { (anos) }\end{array}$} & \multirow{2}{*}{$\begin{array}{c}\text { Examinados } \\
n(\%)\end{array}$} & \multicolumn{2}{|c|}{ Sexo } \\
\hline & & $\begin{array}{c}\text { Masculino } \\
n(\%)\end{array}$ & $\begin{array}{c}\text { Feminino } \\
n(\%)\end{array}$ \\
\hline$<1$ & $11(3,8)$ & $4(36,4)$ & $7(63,6)$ \\
\hline $01-04$ & $60(20,8)$ & $31(51,7)$ & $29(21,6)$ \\
\hline $05-09$ & $70(24,3)$ & $40(57,1)$ & $30(48,3)$ \\
\hline $10-14$ & $84(29,2)$ & $46(54,8)$ & $38(42,9)$ \\
\hline $15-19$ & $63(21,9)$ & $33(52,4)$ & $30(47,6)$ \\
\hline Total & $288(100,0)$ & $154(53,5)$ & $134(46,5)$ \\
\hline
\end{tabular}

Segundo a ocupação, entre o total de indivíduos examinados, $69 \%$ declararam ser estudantes e $56,3 \%$ com ensino fundamental incompleto/completo; $11,5 \%$ já tinham sido submetidos a cirurgias; 1,7\% apresentaram histórico de transfusão de sangue; $3,8 \%$ possuíam piercing e 1,2\% tatuagens; $7,3 \%$ declararam uso de preservativos nas relações sexuais; $2,8 \%$ nunca usava kit próprio de manicure; 0,3\% declarou uso de drogas inaláveis/injetáveis e 3,5\% consumiam bebida alcoólica.

Sobre informações referentes à vacina hepatite B, 78,1\% a desconheciam; para 5,6\% o número de doses da vacina atrapalhava a conclusão do esquema vacinal; 54,9\% não possuíam carteira de vacinação, 1,4\% tinham dificuldade de encontrar a vacina, 3,1\% afirmaram temiam ser vacinados e 9\% assumiram a falta de interesse pela vacina.

A análise sorológica não detectou portadores do VHB entre os comunicantes, caracterizado pela ausência do HBsAg; o marcador anti-HBc total isolado foi detectado em 2,1\% (6/288) amostras reagentes; 4,2\% (12/288) das amostras examinadas foram anti-HBc total/anti-HBs reagentes e 42\% (121/288) apresentaram anti-HBs isolado reagente, atribuído à vacinação onde $73,3 \%$ estavam na faixa etária de um a quatro anos. Verificou-se significância estatística para anti-HBs isolado por realização do teste qui-quadrado de aderência para amostras esperadas iguais, com $p$ (valor) <0,0001 (Tabela 2).

Tabela 2 - Soroprevalência dos marcadores do VHB* entre comunicantes de portadores do VHB, Belém, PA, 2016 - 2018.

\begin{tabular}{|c|c|c|c|c|c|c|c|c|}
\hline \multirow{2}{*}{$\begin{array}{l}\text { Faixa } \\
\text { etária } \\
\text { (anos) }\end{array}$} & \multirow{2}{*}{ N } & \multicolumn{2}{|c|}{ anti-HBc+/anti-HBs+ } & \multicolumn{2}{|c|}{ anti-HBc+ isolado } & \multicolumn{2}{|c|}{ anti-HBs+ isolado } & \multirow{2}{*}{ P-valor } \\
\hline & & $\mathrm{n}(\%)$ & CI $95 \%$ & $n(\%)$ & CI 95\% & $n(\%)$ & CI 95\% & \\
\hline$<1$ & 11 & $4(36,4)$ & $(0,4-0,9)$ & () & $(0,3-0,8)$ & $7(63,6)$ & $(0,3-0,8)$ & \\
\hline $01-04$ & 60 & $4(6,7)$ & $(0,92-4,2)$ & () & $(0,9-4,2)$ & $44(73,3)$ & $(0,9-4,2)$ & \\
\hline $05-09$ & 70 & $1(1,4)$ & $(4,6-9,3)$ & () & $(4,6-9,2)$ & $21(30,0)$ & $(4,6-9,2)$ & $<0,0001^{*}$ \\
\hline $10-14$ & 84 & $1(1,2)$ & $(9,5-14,5)$ & $4(4,8)$ & $(9,4-14,5)$ & $22(26,2)$ & $(9,4-14,5)$ & \\
\hline $15-19$ & 63 & $2(3,2)$ & $(14,8-19,3)$ & $2(3,2)$ & $(14,6-19,6)$ & $27(42,9)$ & $(14,6-19,6)$ & \\
\hline Total & 288 & $12(4,2)$ & & $6(2,1)$ & & $121(42,0)$ & & \\
\hline
\end{tabular}

N= População examinada; Sinal convencional utilizado: - = dado numérico igual a zero, não resultante de arredondamento; *Marcadores do VHB: HBsAg+= portador do VHB; anti-HBc total+/anti-HBs+ = perfil de infecção pregressa pelo VHB; anti-HBc total+ isolado = perfil compativel com infecção pregressa ou atual pelo VHB; anti-HBs+ isolado = perfil compativel com proteção vacinal; "teste qui-quadrado para variável anti-HBs isolado. 
Do total examinado 41,6\% (120/288) receberam esquema completo (três/quatro doses) da vacina hepatite B e 58,4\% (168/288) eram suscetiveis ao VHB. Entre os que receberam esquema completo $51,8 \%$ (73/14l) consistiam em menores de quatro anos de ida- de. Essa diferença entre as doses devacina hepatite B aplicadas foram estatisticamente significativas se comparadas entre as doses de vacina recebidas por ser um grupo com resposta imune, com p<0,000l, conforme apresentado na Tabela 3.

Tabela 3 - Vacina hepatite B entre comunicantes de portadores do VHB, Belém, Pará, Brasil, 2016 a 2018.

\begin{tabular}{|c|c|c|c|c|c|c|}
\hline $\begin{array}{l}\text { Faixa } \\
\text { etária } \\
\text { (anos) }\end{array}$ & $\mathbf{N}$ & 1 dose (\%) & 2 dose (\%) & $3 / 4$ dose $(\%)$ & $\begin{array}{c}\text { Nenhuma dose/ } \\
\text { Não sabe / } \\
\text { (\%) }\end{array}$ & P-valor \\
\hline$<1$ & 11 & $1(9,0)$ & $4(36,4)$ & $4(36,4)$ & $2(18,2)$ & \\
\hline $\mathrm{Ol} \mathrm{-} 04$ & 60 & $1(1,7)$ & $1(1,7)$ & $36(60,0)$ & $22(36,7)$ & $<0,0001^{*}$ \\
\hline $05-09$ & 70 & $1(1,4)$ & $1(1,4)$ & $33(47,0)$ & $35(50,0)$ & \\
\hline $10-14$ & 84 & $1(1,2)$ & ( ) & $30(35,7)$ & $53(63,1)$ & \\
\hline $15-19$ & 63 & () & () & $17(27,0)$ & $46(73,0)$ & \\
\hline Total & 288 & $4(1,4)$ & $6(2,1)$ & $120(41,6)$ & $158(54,9)$ & \\
\hline
\end{tabular}

Nenhuma dose = Não vacinados; Vacinados= com esquema vacinal completo (três/quatro doses); Não vacinados = indivíduos que receberam apenas uma, duas ou nenhuma dose de vacina foi aplicada; Sinal convencional utilizado = , dado numérico igual a zero, não resultante de arredondamento; *teste qui-quadrado para a variável 3a/4a dose.

Em nenhuma das onze amostras examinadas pelo teste de biologia molecular por PCR, foi detectada a presença do DNA do VHB.

\section{DISCUSSÃO}

Compreendemos que, a qualidade de vida da população pode ser influenciada por ações de educação em saúde, porém, faz pouco caso em aceitar e participar, apesar do incipiente interesse e resistência, fatores associados à influência do modelo biomédico, diferente do modelo de saúde atual, que valoriza as ações de prevenção e promoção da saúde ${ }^{14}$, sendo a estratégia de imunizar crianças, adolescentes e indivíduos importante para minimizar riscos e mitigar doenças.

Estudo que mostrou que a distribuição da infecção pelo VHB no Brasil apresentava tendência de redução da prevalência da hepatite $B$, classificando o território nacional como de baixa endemicidade para o $\mathrm{VHB}^{15}$. A presente pesquisa sugeriu um padrão de baixa endemicidade, identificado pela ausência do marcador sorológico HBsAg, de acordo com a classificação de Chen e Chang ${ }^{16}$.

Por ocasião das visitas domiciliares constatou-se que os portadores do VHB, residiam em locais de difícil acesso e em precárias condições de moradia, corroborando com estudo realizado em 2010 que relacionou a infecção por hepatite $\mathrm{B}$ a precárias condições de vida ${ }^{17}$.
A visita domiciliar se apresenta como uma estratégia de reconhecida importância dos serviços de saúdes, como ferramenta no combate à redução da pobreza e de seus impactos sanitários derivados ${ }^{18}$.

O grupo estudado foi considerado de risco elevado para infecção pelo VHB por estar a mercê, em relação às questões de comportamento, sem proteção adequada relacionada a vida sexual, por utilizarem álcool e drogas, pelo modismo quanto a aplicação de tatuagens e piercings, fatores esses associados as características normais de seu desenvolvimento psicossocial, lhes proporcionando uma sensação de invulnerabilidade e imortalidade, não possibilitando a compreensão das consequências desses comportamentos para o futuro, o que também foi percebido em estudo sobre adolescentes e a vacina contra hepatite $\mathrm{B}^{8}$.

A pesquisa atual assemelhou-se ao estudo de prevalência realizado em diversas capitais brasileiras e no Distrito Federal, que caracterizou ausência de portadores do VHB entre os participantes, apesar de ser esperado encontrar um percentual de resultados reagentes por tratar-se de uma população composta por individuos submetidos a situações de risco ${ }^{19}$.

Estudo realizado no Irã identificou que não existia um programa de rotina para triagem de indivíduos infectados pelo VHB na região estudada, portanto havia a possibilidade da infecção ser transmitida antes da realização de um teste diag- 
nóstico, o que pode ter acontecido entre os participantes da presente pesquisa em relação aos infectados ${ }^{20}$.

O resultado atual detectou a falta de interesse como principal causa da não vacinação em 9\% dos examinados, diferente do estudo realizado pela Estratégia Saúde da Família (ESF), em Volta Redonda, Rio de Janeiro, em 2013, onde 37\% citou o esquecimento como motivo principal ${ }^{21}$.

Estudo realizado com enfermeiros da ESF apontou que a imunização foi citada apenas por um participante como uma intervenção para prevenir doenças, bem como pouco relatada entre as intervenções de prevenção primária. Sentiu-se a necessidade de ampliação desse conhecimento entre a equipe de enfermagem, de forma a contribuir com a população, especialmente pelo exposto na pesquisa atual sobre o comportamento de seus integrantes em relação a não se vacinarem $^{22}$.

A caderneta de vacinação se caracterizou como uma das dificuldades encontradas, considerando que 54,9\% dos entrevistados não possuiam o documento. Percebeu-se que uma das maneiras de solucionar o problema das perdas seria implantar um sistema informatizado adequado, para consolidar as informações sobre vacinas, corroborando com Santos e Oliveira ${ }^{23}$, quando citaram a falta de um sistema de informação personalizado como uma das barreiras do sistema de saúde dentro dos desafios da vacinação.

$\mathrm{Na}$ verificação da resposta imune à vacina hepatite $\mathrm{B}$ a investigação identificou uma taxa de 42\% (121/288) de indivíduos com anti-HBs isolado, atribuída à vacinação, sendo que a maior cobertura vacinal estava na faixa etária de um a quatro anos com 36,4\%. Ao analisar a população de zero a nove anos foram encontrados $59,6 \%$ de anti-HBs reagente isolado, inferior a estudo desenvolvido na cidade de Buriticupu, Maranhão, na região leste da Amazônia brasileira que alcançou percentual maior que $70 \%$ de vacinados entre crianças de zero a dez anos, e também inferior ao estudo entre crianças e adolescentes do Egito, com esquema vacinal completo que encontrou proteção sorológica de 57,2\% $\%^{17,24}$

A cobertura vacinal do município de Belém do Pará ficou heterogênea para o período analisado, foi abaixo da média nacional, similar ao que aconteceu em estudo na cidade de Trindade, Estado de Goiás, que obteve cobertura insatisfatória na maior parte dos anos, considerando que a base da prevenção da hepatite B é a vacina, que confere $90 \%$ a 95\% de proteção aos indivíduos imunocompetentes, com esquema vacinalapropriado $25-27$

A prevalência de $58,3 \%$ de não vacinados encontrada pelo estudo, foi superior ao encontrado em dois municípios da Microregião de Parauapebas, sudeste do estado do Pará, onde no município de Canaã dos Carajás detectou-se prevalência de $44,1 \%$ e no município de Curionópolis $36,4 \%$ de suscetíveis ao $\mathrm{VHB}^{28}$

Em relação a faixa etária das crianças com atraso vacinal, a maior prevalência foi entre os menores de um ano com $66,7 \%$, superior ao encontrado em estudo, que identificou 25,1\% de crianças com maioria na faixa etária acima de três anos com esquema vacinal incompleto ${ }^{29}$.

\section{Limitações do estudo}

O estudo apresentou como principais limitações: o desconhecimento do estado de portador do VHB pelos investigados; a falta de conhecimento da importância da vacina, impactando na resposta da cobertura vacinal; as dificuldades relacionadas à coleta de sangue; e a presença do responsável quando da realização do inquérito inibindo as informações dadas pelos jovens por ocasião da entrevista.

Nas visitas domiciliares houve dificuldades pela fragilidade do sistema de segurança pública, mudanças frequentes de endereço, resistência das pessoas em receber a equipe e em participar do projeto, comportamentos associados à desinformação.

\section{Contribuições para a prática}

O estudo contribuirá para a elevação do conhecimento dos profissionais da saúde, sobretudo os de Enfermagem, na área de Hepatologia, ressaltando a importância da busca ativa de casos na vigilância epidemiológica da hepatite B. Ao enfermeiro quando da elaboração e desenvolvimento de ações como educação em saúde com a comunidade, melhoria da cobertura vacinal, uma vigilância epidemiológica mais ativa de acompanhamento dos comunicantes de portadores do VHB insipiente na atenção primária à saúde.

\section{CONCLUSÃO}

A ausência de portadores do VHB, entre comunicantes de portadores de hepatite $B$, abaixo de 20 anos de idade, no município de Belém, sugere uma baixa endemicidade nesse grupo populacional, mesmo com a cobertura vacinal abaixo do preconizado pelo Programa Nacional de Imunização (PNI).

Os achados relativos ao esquema vacinal incompleto e os resultados não reagentes ou não realizados para o teste anti-HBs evidenciaram uma realidade preocupante entre os adolescentes e crianças, sobretudo os comunicantes de portadores do VHB, vislumbrando a falta de proteção adequada e alta frequência de indivíduos suscetíveis, expostos ao risco de infecção, sugerindo a necessidade de incremento dos programas de educação em saúde.

Os resultados encontrados permitiram inferir a necessidade de maior atenção para a população avaliada, maior controle dos comunicantes com realização de visitas domiciliares e exames sorológicos para controle dessa população; regis- 
tro adequado das doses de vacina, orientação aos responsáveis, fortalecimento do PNI e incrementação das atividades de vigilância epidemiológica, além de contribuir informando a comunidade científica sobre a situação dos comunicantes de portadores do VHB.

Em razão das taxas de prevalência na região Amazônica brasileira, sugerimos a realização de novos estudos dirigidos sobre a prevalência do VHB em faixa etária de maiores de vinte anos e avaliação da resposta imune em amostras da população.
Contribuições dos Autores: Todos os autores participaram de todas as etapas do trabalho.

Financiamento: Este estudo foi apoiado por financiamento do Ministério da Saúde.

Agradecimentos: Os autores gostariam de agradecer a todos os participantes que tornaram esta pesquisa possivel e ao Instituto Evandro Chagas, Secretaria de Vigilância em Saúde, servidores do Ministério da Saúde pela colaboração no desenvolvimento do estudo.

\section{REFERÊNCIAS}

Ministério da Saúde (BR). Secretaria de Vigilância em Saúde. Hepatites Virais. Guia de Vigilância em Saúde. Brasília: Ministério da Saúde; 2019. Cap. 4, p. 264-276. [Internet]. 2019 [cited2019jun13]. Available from: http://portalarquivos2.saude.gov.br/images/ pdf/2019/junho/25/guia-vigilancia-saude-volume-unico-3ed.pdf.

World Health Organization (WHO). Hepatitis B. United States of America [Internet]. 2018 [cited 2019 jun 13]. Available from: https://www.who.int/en/news-room/fact-sheets/detail/hepatitis-b.

Locarnini S, Hatzakis A, Chen D-S, Lok A. Strategies to control hepatitis B: Public policy, epidemiology, vaccine and drugs. J Hepatol [Internet]. 2015 [cited 2019 out 16]; 62(1Suppl):S76-S86. Available from: https://www.sciencedirect.com/science/article/pii/ S0168827815000495

Maclachlan JH, Locarnini S, Cowie BC. Estimating the global prevalence of hepatitis B. The Lancet [Internet]. 2015 [cited 2019 jul 15]; 386:515-1517. Available from: https://www.thelancet.com/journals/lancet/article/PIISO140-6736(15)61116-3/fulltext.

Ministério da Saúde (BR). Secretaria de Vigilância em Saúde. Departamento de Doenças de Condições Crônicas e Infecções Sexualmente Transmissiveis. Protocolo clinico e diretrizes terapêuticas para prevenção da transmissão vertical de HIV, sífilis e hepatites virais. Brasilia: Ministério da Saúde; 2019. Cap. 28, p. 208-232. [Internet]. 2019 [cited 2019 dez 16]. Available from: http:// www.aids.gov.br/pt-br/pub/2015/protocolo-clinico-e-diretrizes-terapeuticas-para-prevencao-da-transmissao-vertical-de-hiv. Pereira VRZB, Wolf JM, Luz CAS, Stumm GZ, BoeiraTR, Galvan J, Simon D, Lunge VR, et al. Risk factors for hepatitis B transmission in South Brazil. Mem Inst Oswaldo Cruz, [Internet]. 2017 [cited 2020 abr 11];112(8):544-550. Available from: http://www.scielo.br/ pdf/mioc/vl12n8/0074-0276-mioc-112-8-0544.pdf

Ministério da Saúde (BR), Secretaria de Vigilância em Saúde. Guia de Vigilância em Saúde. Brasília: Ministério da Saúde; 2017. Cap. 4, p. 255-299. [Internet]. 2017 [cited 2019 jan7]. Available from: http://biblioteca.cofen.gov.br/wpcontent/uploads/2017/10/volume_2_guia_de_vigilancia_em_saude_2017.pdf.

Coutinho, MFG. Adolescência: vacina contra hepatite B. Adolescência \& Saúde, [Internet]. 2010 [cited 2019 nov 19]; 7(1):23-30. Available from: https://s3-sa-east-1.amazonaws.com/publisher.gnl.com.br/adolescenciaesaude.com/pdf/v7nla05.pdf.

Orlando R, Foggia M, Maraolo AE, Mascolo S, Palmiero G, Tambaro O, et al. Prevention of hepatitis B virus infection: from the past to the future. Eur J ClinMicrobiol Infect Dis [Internet]. 2015 [cited 2019 Jun 23]; 34(6):1059-1070. Availablefrom: https://doi. org/10.1007/s10096-015-2341-x

10.Ministério da Saúde (BR). Secretaria de Vigilância em Saúde. Boletim epidemiológico. Hepatites Virais. Brasilia: Ministério da Saúde; 2019. p. 14-21. [Internet]. 2019 [cited2020 jan 14]. Available from:http://www.aids.gov.br/pt-br/pub/2019/boletim-epidemiologico-de-hepatites-virais-2019.

11. Ministério da Saúde (BR), Secretaria de Vigilância em Saúde. Guia de Vigilância Epidemiológica. Brasilia: Ministério da Saúde; 2010. Cap. 6, p. 23-45. [Internet]. 2010 [cited $2018 \mathrm{dez}$ 11]. Available from: https://bvsms.saude.gov.br/bvs/publicacoes/guia_vigilancia_epidemiologica_7ed.pdf

12. Sitnik R, Pinho JR, Bertolini DA, Bernardini AP, Da Silva LC, Carrilho FJ. Hepatitis B virus genotypes and precore and core mutants in Brazilian patients. Journal of Clinical Microbiology [Internet]. 2004 [cited 2019 set 25]; 42(6):2455-2460. Available from: https://europepmc.org/backend/ptpmcrender.fcgi?accid=PMC427827\&blobtype=pdf.

13. Gomes-Gouvêa MS, Soares MC, Bensabath G, De Carvalho-Mello IM, Brito EM, Souza OS, Queiroz AT, Carrilho FJ, Pinho JR. Hepatitis B virusandhepatitis delta virusgenotypes in outbreaksoffulminanthepatitis (Labreablackfever) in the western BrazilianAmazon region. J GenVirol [Internet]. 2019 [cited 2019 abr 25]; 90:2638-2643, 2009. Available from: https://www.arca.fiocruz.br/ 
handle/icict/27391

14. Silva JMA, Batista BD, Carmo AP, Gadelha MMT, Andrade ME, Fernandes MC. Dificuldades experienciadas pelos Agentes Comunitários de Saúde na realização da educação em saúde. Enferm Foco [Internet]. 2019 [cited 2020 mai]; 10(3):8287. Available from: http://revista.cofen.gov.br/index.php/enfermagem/article/view/1818/577.

15. Souto FJ. Distribution of hepatitis B infection in Brazil: the epidemiological situation at the beginning of the 21 Century. Rev. Soc. Bras. Med. Trop [Internet]. 2016 [cited 2020 jan 30]; 49(1):1123. Available from: http://www.scielo.br/pdf/rsbmt/ v49nl/00378682rsbmt1015900037868201762015.pdf.

16. Chen ST., Chang MH. Epidemiology and Natural History of Hepatitis B in Children. In: Jonas MM, editor. Viral Hepatitis in Children: unique features and opportunities (Clinical gastroenterology). New York: Springer; 2010. p. 13-28.

17. El Khouri M, Cordeiro Q, Luz DABP, Duarte LS, Gama MEA, Corbett EP. Endemic hepatitis B and C virus infection in a Brazilian eastern amazon region.Arq. Gastroenterol [Internet]. 2010 [Cited 2020 abr 01]; 47(1):35-41. Available from: http://www.scielo.br/ scielo.php?script=sci_arttext\&pid=S000428032010000100007\&lng=en\&nrm=iso.

18. Minkovitz CS, Neill KMGO, Duggan AK. Home visiting: a service strategy to reduce poverty and mitigate its consequences. Acad Pediatr [Internet]. 2016 [cited 2019 dez 18]; 16(3Suppl):S105-11. Available from: https://www.hvresearch.org/wp-content/ uploads/2018/01/PIIS1876285916000218.pdf.

19. Universidade de Pernambuco. Núcleo de Pós-graduação. Estudo de prevalência de base populacional das infecções pelos virus das hepatites A, B e C nas capitais do Brasil. Recife: Núcleo de Pós-graduação, Universidade de Pernambuco [Internet]. 2010 [Citado 2019 ago 22]. Available from: http://www.aids.gov.br/sites/default/files/anexos/publicacao/2010/50071/estudo_prevalencia_hepatites_pdf_26830.pdf

20. Sali, S, Azarmmanesh S, HediyehGhalikhani H, Vaezjalali M.Phylogenetic Analysis of hepatitis B virus among household members with HBV chronic infection. Avicenna Journal of Medical Biotechnology [Internet]. 2019 [Cited 2019 Jul]; 11(3):221-228. Available from: https://www.ncbi.nlm.nih.gov/pmc/articles/PMC6626507/pdf/AJMB-11-221.pdf.

21. Carneiro SG, Ribeiro TT, Cardoso MDT, Strapasson JF, Costa AFB, Guina FD. Evaluation of vaccination's coverage among children aged from 2 months to 5 years in family halth strategy. Cadernos UniFOA [Internet]. 2013 [Cited 2020 Abr 02]; 22:63-72. Available from: https://www.google.com/search?client=firefoxbefq=edi\%C3\%A7\%C3\%A30+n\%C2\%BA22\%3A6372.+http\%3A\%2F\%2Frevista.unifoa.edu.br.

22. Moll MF, Boff NN, Silva PS, Siqueira TV, Ventura CAA. O enfermeiro na saúde da família e a Promoção de saúde e prevenção de Doenças. Enferm Foco [Internet]. 2019 [cited 2020mai]; 10(3):134140. Available from: http://revista.cofen.gov.br/index.php/enfermagem/article/view/2001/570.

23. Santos EP, Oliveira MMM. Desafios da vacinação. Rev Imuniz [Internet]. 2018 [Cited 2020 fev 02]; 11(4):10-15. Available from: .

24. Salama II, Sami SM, Said ZNA, El-Sayed MH, El Etreby LA, Rabah TM et al. Effectiveness of hepatitis B virus vaccination program in Egypt: multicenter national project. World J Hepatol [Internet]. 2015 [cited 2019 sep 23]; 7(22):2418-26. Available from: https:// www.ncbi.nlm.nih.gov/pmc/articles/PMC4598613/pdf/WJH-7-2418.pdf

25. Ministério da Saúde (BR). Secretária de Vigilância em Saúde. Programa Nacional de Imunizações (PNI): 40 anos. Brasília: Ministério da Saúde; 2013. p. 118-180. [Internet]. 2013 [cited 2019 nov 21]. Available from: https://bvsms.saude.gov.br/bvs/publicacoes/ programa_nacional_imunizacoes_pni40.pdf.

26. Souza CA, Machado RDS, Rocha BAM. Cobertura vacinal da hepatite B e fatores associados. Rev Escol de Saúde Faculd União de Goyazes. [Internet]. 2013 [Cited 2019 nov]; 7(1):2-18. Available from: http://fug.edu.br/revistas/index.php/Vitaet Sanitas/article/ view/38/30.

27. Ministério da Saúde (BR). Fundação Nacional de Saúde. Manual de normas de vacinação. Brasília: Ministério da Saúde; 2001.72 p. [Internet]. 2001 [cited 2016 jan 19]. Available from:

http://bvsms.saude.gov.br/bvs/publicacoes/funasa/manu_normas_vac.pdf.

28. Nunes HM, Sarmento VP, Malheiros AP, Paixão JF, Costa OSG, Soares MCP. As hepatites virais: aspectos epidemiológicos, clinicos e de prevenção em municípios da Microregião de Parauapebas, sudeste do estado do Pará, Brasil. RevPan-Amazônica de Saúde [Internet]. 2017 [cited 2020 Abr 03]; 8(2):29-35. Available from: http://scielo.iec.gov.br/php?script=sci_arttextEpi$d=S 2176622320170002000298$ lng=pt. http://dx.doi.org/10.5123/s2176-62232017000200004.

29. Bispo WF, Santos PFBB, Wesp LHS, Medeiros ER, Souza PB, Galvão MC. Situação vacinal contra hepatites A e B em crianças da educação infantil. EnfermFoco [Internet]. 2017 [cited2019out]; 8(4):3136. Available from: http://revista.cofen.gov.br/index.php/ enfermagem/article/view/1346/pdf. 